\title{
COMUNIDADES DE PRÁTICAS COMO ESPAÇOS DE FORMAÇÃO INICIAL NA EDUCAÇÃO DE JOVENS E ADULTOS
}

\author{
COMUNIDADES DE PRÁCTICAS COMO ESPACIOS DE FORMACIÓN INICIAL EN \\ LA EDUCACIÓN DE JÓVENES Y ADULTOS
}

COMMUNITIES OF PRACTICES AS SPACES OF INITIAL TRAINING IN EDUCATION OF YOUTH AND ADULTS

Maria Clarisse VIEIRA ${ }^{1}$

RESUMO: O artigo analisa as significações atribuídas à formação inicial em educação de jovens e adultos (EJA), desenvolvida por graduandos da Faculdade de Educação da UnB. Com base no conceito de Comunidades de Práticas, nas contribuições da educação popular e da perspectiva histórico-Cultural o texto reconstrói esta experiência por meio da análise de diários de bordo e relatórios elaborados pelos estudantes de graduação no período de 2013 a 2016, nas disciplinas Projeto 3 e 4, componentes do currículo de Pedagogia. O contato com os educandos da EJA e a reflexão na e sobre a prática educativa forja no graduando uma sensibilidade/compromisso em relação a essa realidade, por meio da pesquisa-ação, da vivência e do desenvolvimento de uma prática pedagógica pautada na escuta sensível e no diálogo.

PALAVRAS-CHAVE: Comunidades de prática. Formação de educadores. Educação popular. Educação de jovens e adultos.

RESUMEN: El artículo analiza las significaciones atribuidas a la formación inicial en educación de jóvenes y adultos (EJA), desarrollada por graduandos en la Facultad de Educación de la UnB. Con base en el concepto de Comunidades de Prácticas, en las contribuciones de la educación popular y de la perspectiva histórico-Cultural el texto reconstruye esta experiencia por medio del análisis de diarios de a bordo e informes elaborados por los estudiantes de graduación en el período de 2013 a 2016, en las disciplinas Proyecto 3 y 4, componentes del currículo de Pedagogía. El contacto con los educandos de la EJA y la reflexión en y sobre la práctica educativa forja en el graduando una sensibilidad / compromiso en relación a esa realidad, a través de la investigación-acción, de la vivencia y del desarrollo de una práctica pedagógica pautada en la escucha sensible y en el diálogo.

PALABRAS CLAVE: Comunidades de práctica. Formación de educadores. Educación popular. Educación de jóvenes y adultos.

ABSTRACT: The article analyzes the meanings attributed to initial training in youth and adult education (EJA), developed for university students at the Faculty of Education of UnB. Based

${ }^{1}$ Universidade de Brasília (UnB), Brasília - DF - Brasil. Professora Associada da Faculdade de Educação e do Programa de Pós-graduação em Educação. Pedagoga com mestrado em Educação pela Universidade Federal de Uberlândia (2000) e doutorado em Educação pela Universidade Federal de Minas Gerais (2006). ORCID: <http://orcid.org/0000-0001-5924-0488>. E-mail: mclarissev@yahoo.com.br 
on the concept of Communities of Practice, the contributions of popular education and the historical-cultural perspective, the text reconstructs this experience through the analysis of logbooks and reports prepared by undergraduate students from 2013 to 2016 in the disciplines Project 3 and 4, components of the Pedagogy curriculum. The contact with the students of the EJA and the reflection in and on the educational practice forges in the graduating a sensitivity I commitment in relation to this reality, through the action research, the experience and the development of a pedagogical practice based on the sensitive listening and dialogue.

KEYWORDS: Communities of practice. Training of educators. Popular education. Education of young people and adults.

\section{Introdução}

O Brasil adentra a segunda década do novo século com um desafio ainda por superar: a baixa escolarização de sua população em geral e, em especial, das pessoas jovens e adultas. Segundo dados da Pesquisa Nacional por Amostra de Domicílios - PNAD 2015 (BRASIL, 2016), existem aproximadamente 12,9 milhões de pessoas maiores de 15 anos analfabetas, o que corresponde a $8 \%$ da população. Esse índice aumenta para $17,1 \%$ ou cerca de 27,6 milhões de pessoas, quando ampliamos o conceito para analfabetismo funcional (pessoas acima de 15 anos e com menos de quatro anos de estudo). Este é o público potencial da Educação de Jovens e Adultos (EJA) que é composto por pessoas que, não tendo tido o acesso e/ou permanência na escola, em idade que lhes era de direito, retornam hoje, buscando o resgate desse direito. A maior parte dos professores que se propõem a ensinar o público da EJA não possui a qualificação necessária para essa tarefa. E, portanto, sem a devida qualificação passam a desenvolver a prática pedagógica ignorando as especificidades e peculiaridades dos sujeitos em processo de escolarização.

Não obstante este cenário, algumas universidades, por meio de atividades ligadas à pesquisa e extensão tem desenvolvido ações que se dirigem à formação em Educação de Jovens e Adultos. Este artigo busca contribuir com esta reflexão por meio da experiência do Grupo de Ensino, Pesquisa e Extensão em Educação Popular e Estudos Histórico-Culturais - GENPEX. Para tanto, o texto fundamenta-se nas contribuições da educação popular, da teoria histórico cultural de Vygotsky e dos contemporâneos Lave e Wenger (1991, 1998), estudiosos dessa teoria, que a partir dela, desenvolveram a teoria da aprendizagem situada, tendo em vista a dimensão da experiência histórica e cultural humana. A partir do conceito de comunidades de práticas (LAVE \& WENGER,1991), o texto analisa diários de bordo e relatórios elaborados pelos graduandos no período de 2013 a 2016, nas disciplinas Projeto 3 e 4, componentes do currículo de Pedagogia vigente desde 2003. Busca-se compreender as significações atribuídas 
pelos graduandos a formação inicial vivenciada na EJA, bem como o processo de transformação pessoal e profissional decorrente do contato com educandos jovens em adultos.

\section{Gênese das atividades do Genpex e relação com o currículo de Pedagogia da UnB}

O grupo de Ensino, Pesquisa e Extensão em Educação Popular e Estudos Históricoculturais - Genpex tem suas origens relacionadas ao movimento de ocupação da Região administrativa do Paranoá, iniciado com a construção da capital Federal, quando brasileiros oriundos de diversas regiões do País, migram para essa região e iniciam um processo de luta pela moradia e fixação. A luta em prol da posse definitiva da terra estrutura-se e torna-se sistematizada, a partir dos anos 1970 e 1980, por meio da mobilização de um grupo de jovens, ligados à igreja católica, que iniciam um trabalho político pastoral de conscientização da comunidade. Este grupo se organiza em uma associação de moradores e passa a pressionar, de forma mais efetiva, o poder público pela fixação da população e o fornecimento de serviços básicos, como educação, saúde, água, luz, esgoto, segurança e transporte.

É neste contexto, que percebem a Educação de Jovens e Adultos, como forma de fortalecer a luta e fixação da população na cidade, visto que a maioria dos moradores não era alfabetizada. Inicialmente, procurou-se apoio da igreja católica local. Mas para que o trabalho se expandisse, necessitavam de apoio pedagógico. Como naquele momento esse apoio era negado pelo Estado foram buscá-lo, em 1986, na Faculdade de Educação da Universidade de Brasília. Desde então, a UnB desenvolve em parceria com o Movimento Popular - Centro de Desenvolvimento e Cultura do Paranoá (CEDEP), trabalho educativo voltado à Educação e formação de educadores (as) de Jovens e Adultos na Região administrativa do Paranoá/Itapoã.

O objetivo da cooperação GENPEX/FE/UnB e CEDEP é contribuir pedagogicamente com o processo de alfabetização e formação de alfabetizadores de jovens e adultos do Paranoá e Itapoã e, também, com o processo de formação dos/as pedagogos/as e demais licenciados/as da Universidade de Brasília. Com registro no Conselho Nacional de Desenvolvimento Tecnológico e Científico (CnPq) desde 2000, o GENPEX agrega em sua composição estudantes de graduação em Pedagogia que atuam por meio dos projetos 4 fases 1 e 2, estudantes de mestrado e doutorado em educação, professores e servidores da Secretaria de Educação do DF, e outros membros pesquisadores da Universidade de Brasília e outras instituições de nível superior. 
A atuação do grupo de pesquisa é por meio da pesquisa-ação com foco na perspectiva histórico-cultural que entende a práxis como fundamental para a construção de um processo educativo real concreto e significante para a formação de um sujeito de amor, poder e saber (VIEIRA; REIS; SOBRAL, 2015, p. 15). A pesquisa-ação é um tipo de metodologia de pesquisa social com base empírica, concebida e realizada em estreita associação com uma ação "ou com uma resolução de um problema coletivo, e no qual os pesquisadores e os participantes representativos da situação ou problema estão envolvidos de modo cooperativo ou participativo" (THIOLLENT, 1985, p. 14). A pesquisa-ação não é constituída apenas pelo caráter participativo, mas inclui uma dimensão de produção de conhecimento, que pode ser útil não apenas para a coletividade considerada na investigação, mas para um público mais amplo.

O processo de ação-reflexão-ação, realizado no interior da escola e dos movimentos sociais, possibilita a implicação do pesquisador, momento no qual este se engaja pessoal e coletivamente, em uma práxis científica “em função de sua história familiar e libidinal, de suas posições passada e atual nas relações de produção e de classe, de seu projeto sociopolítico em ato" (BARBIER, 2002, p. 101). Este engajamento vem se traduzindo na parceria que há mais de 30 anos se construiu junto ao movimento popular do Paranoá-Itapoã, realizada semanalmente nas salas de alfabetização e no planejamento que a universidade realiza.

Esta concepção de pesquisa vai ao encontro da ideia de Comunidades de Práticas. Este conceito teve início com o trabalho de Ethienne Wenger (1998). Segundo ele, a aprendizagem é uma prática social, no qual o sujeito participa de maneira ativa nas práticas das comunidades e sustenta o compromisso mútuo na ação; por meio do compartilhamento de recursos históricos e sociais, que implicam na construção de identidades em relação a essas comunidades (WENGER, 1998). Suas raízes estão ligadas às ideias de Vygotsky, para o qual o pensamento e a consciência são determinados pelas atividades realizadas com outras pessoas em um meio sociocultural determinado.

Para Lave e Wenger (1991, p. 14), as Comunidades de Prática, consistem "na membresia e dependem dela, incluindo as biografias /trajetórias, relações e práticas que as caracterizam”. Ou seja, a prática requer um modo de falar de recursos históricos e sociais compartilhados, dos sistemas, ou quadros de referências e perspectivas que possam sustentar o compromisso mútuo na ação da Comunidade, em que a continuidade das atividades se define como buscas valiosas e a participação dos membros é reconhecida como competente, pois há uma identidade própria na e da Comunidade de Prática (WENGER, 1998).

Em consonância com esta ideia, o Projeto Acadêmico (PA) da Faculdade de Educação da UnB (FE), afirma que o egresso do curso será um pedagogo com registro de 
professor/educador habilitado a trabalhar em espaços escolares e não escolares, admitindo perspectivas diferenciadas de inserção no mercado de trabalho. O currículo da FE é organizado por disciplinas obrigatórias e optativas, projetos, oficinas e seminários interdisciplinares. O curso de Pedagogia da FE-UnB não se organiza em uma grade curricular fechada, mas por meio de uma proposta aberta, apoiada na ideia de fluxo curricular. A base docente e a formação prático-teórica ocorrem por meio da inserção de projetos, ou seja, "atividades orientadas, de observação, de regência, de investigação, de extensão, de busca bibliográfica [...] tendo como referencial a vida concreta das organizações onde os fatos e as situações educativas acontecem" (UNB, 2002, p. 15). O objetivo de se trabalhar por meio de projetos é a inserção gradativa na vida universitária e na profissão docente, e a possibilidade de vivência prática do fazer pedagógico. É uma busca de integração entre teoria e prática ao longo de todo o curso. Na lógica dos projetos emerge a pesquisa, inserida na articulação prático-teórica substituindo a perspectiva de que os estágios devam ocorrer apenas ao final de curso, mas essa vivência deve ser ao longo de 8 semestres, culminando com o Trabalho de Conclusão de Curso.

De acordo com o Projeto Acadêmico, o currículo do curso de Pedagogia favorece a vivência de duas modalidades de atividade acadêmica: espaços disciplinares cuja ênfase é posta na apropriação de teorias e conceitos e, de outro lado, os espaços curriculares denominados projetos. O Projeto 1 tem por objetivo acolher os estudantes e inseri-los no contexto da Faculdade e da Universidade e, mais especificamente, na profissão de pedagogo. O Projeto 2 busca discutir o campo de atuação da Pedagogia, com base no estudo e investigação epistemológica da Educação. O Projeto 3 busca oferecer vivência prática do fazer pedagógico em diferentes contextos institucionais, articulando, no processo formativo, as atividades de extensão, pesquisa e ensino. O Projeto 4 visa à imersão do aluno de Pedagogia nas práticas educativas que ocorrem no contexto escolar formal, seja este vinculado a instituições públicas, particulares ou a organizações/movimentos sociais. Também chamado de TCC, o Projeto 5 constitui a culminância desse itinerário acadêmico.

Com base nessa organização curricular, A FE/UnB forma professores no curso de Pedagogia, mediante a oferta de disciplinas teóricas-práticas que compõem o eixo pedagógico. A Educação de Jovens e Adultos é tratada nos espaços relativos aos Projetos 3,4 e 5 e também em disciplina optativa no currículo do curso de Pedagogia. É importante mencionar que, no momento atual, esta proposta curricular encontra-se em processo de reformulação, e terá, como matéria obrigatória a disciplina Educação de Jovens, adultos e idosos trabalhadores (EJAIT). 


\section{A práxis desenvolvida na formação docente e na alfabetização de jovens e adultos}

O referencial teórico do Genpex tem como fundamento a perspectiva histórico-cultural que considera a constituição do sujeito parte intrínseca do desenvolvimento humano. Esta perspectiva incorpora a compreensão não apenas dos processos psicologizado da aprendizagem da criança, mas também contempla o sujeito adulto aprendiz em suas diferenças e singularidades, pois segundo Vygotsky a diferença entre aprendizagem da criança e do sujeito adulto "consiste nas diversas relações das aprendizagens com o processo de desenvolvimento" (VYGOTSKY, 2006, p. 116), o qual requer vivências e experiências em que o sujeito participa cotidianamente nos contextos sociais que atua. Em outras palavras, essas relações entre aprendizagem e desenvolvimento do adulto implicam em que o sujeito vivencie o processo de "converter-se em participante pleno de uma prática sociocultural, que compromete os propósitos de aprender de uma pessoa e configura o significado da aprendizagem" (LAVE \& WENGER, 1991, p. 1), ou seja, o sujeito aprende e desenvolve-se a partir das suas relações e práticas sociais.

As relações sociais do indivíduo e seu contexto cultural, que viabilizam a tessitura dessas redes, entretanto, não ocorrem de forma direta, mas sim a partir de processos de mediação simbólica, efetuados através de instrumentos e signos constituídos historicamente. Vygotsky investigou as funções psicológicas superiores, com ênfase na sua gênese, incluindo tanto a filogênese, como a ontogênese, além de estudar instrumentos e signos como mediadores da construção da conduta e desenvolvimento humano, o que distinguiu seus estudos das teorias dominantes da época como a reflexologia e o behaviorismo.

Vygotsky (1996, p. 193) afirma que:

Cremos que o sistema de análise psicológica adequado para desenvolver uma teoria deve partir da teoria histórica das funções psíquicas superiores, que por sua vez se apoia em uma teoria que responde à organização sistemática e ao significado da consciência no homem. Essa doutrina atribui um significado primordial a: a) a variabilidade das conexões e relações interfuncionais; b) a formação de sistemas dinâmicos complexos integrantes de toda uma série de funções elementares; e c) a reflexão generalizada da realidade na consciência.

Essa forma de pensar o homem no aspecto histórico-cultural, desenvolvida por Vygotsky é considerada relevante pelo fato de lidar com sujeitos humanos, e como tal a importância das relações sociais, da história de vida, da fala, da escuta e da cultura em que estão inseridos. Em consonância com esta perspectiva, o trabalho pedagógico do Genpex é composto pelos seguintes eixos: o acolhimento (amorosidade), a discussão de situações-problemadesafios e os usos de textos coletivos. 
Um dos diferenciais do processo de alfabetização desenvolvido é o acolhimento, a "amorosidade" com que as alfabetizandos (a) são tratados (FREIRE, 1996). Parte-se do pressuposto que quando se atua com pessoas as quais foi negado o acesso à escola e a própria língua escrita, trabalha-se com pessoas excluídas de várias formas e que não têm como habitual tal acolhimento. De um modo geral, o público da EJA carrega em si um sentimento de baixa autoestima, presente em afirmações de que "nada sei, "nada sou" e nada posso. A baixa autoestima, que se relaciona diretamente com o processo de aprendizagem, é decorrente do processo de exclusão social, política, econômica e histórica vivenciadas pelas desigualdades do país. Neste sentido, este eixo tem como foco o dessilenciamento ou "destramelamento da pessoa". Ser acolhido no processo de alfabetização garante o bem-estar do educando e consequentemente a permanência do mesmo no ambiente escolar. Trata-se de propiciar uma abertura do "eu" ao "outro". Essa abertura é fundamental para a permanência e para o desenvolvimento integral do sujeito que retorna à escola com medos, anseios e preconceitos, consubstanciados pela sua condição de analfabetos.

A situação-problema-desafio se refere "às necessidades amorosas/afetivas, econômicas, financeiras, sociais e culturais. Essas necessidades caracterizam o cotidiano vivido/enfrentado pelos moradores do Paranoá" (VIEIRA; REIS; SOBRAL, 2015, p. 18). Em meio ao espaço de diálogo entre universidade e comunidade surgem essas situações-problema-desafio, que são constituídas por propostas político-pedagógicas que vão ao encontro das necessidades levantadas pela comunidade. Elas são "escolhidas com discussão, defesa de posição, votação com maioria simples ou absoluta. Tornam-se o eixo dorsal de referência do processo alfabetizador" (VIEIRA; REIS; SOBRAL, 2015, p. 20). A partir das discussões surgem os encaminhamentos individuais e coletivos com o propósito de superar essas questões.

O texto coletivo é o processo de transcrição da palavra oral em texto escrito. A construção do texto coletivo inicia-se no momento em que alfabetizandos e alfabetizadores, num diálogo tecido com base na escolha da situação-problema-desafio se expressam e discutem as dificuldades vivenciadas no dia-a-dia. A partir dos registros oriundos da oralidade são produzidos textos que se transformam em atividades, as quais envolvem a língua portuguesa, matemática, história, geografia e outros conteúdos. O intuito é valorizar a voz dos educandos, trabalhar a partir de questões propostas por eles mesmos e que dizem respeito a sua realidade e encaminhar soluções aos problemas vividos na comunidade. 


\section{Desafios da ação do movimento popular na rede pública de ensino do Paranoá}

Até 2015, as atividades de educação e formação de educadores de jovens e adultos do GENPEX eram realizadas nos espaços comunitários. No entanto, a partir de um processo avaliativo realizado pelo GENPEX e CEDEP constatou-se a necessidade de continuar o acompanhamento de egressos da alfabetização do CEDEP na rede pública de ensino. A aproximação do espaço da escola pública teve como pano de fundo algumas questões: como constituir na escola pública o ideário da educação popular, com base na experiência acumulada em leituras, vivências e experimentações? É possível superar a concepção cartorial, aligeirada e compensatória da EJA, em favor de uma experiência que se paute na constituição de sujeitos de amor, poder e saber?

A partir destas indagações, em março de 2015, decorrente de uma articulação interinstitucional entre Movimento Popular, UnB e Escola Pública, foi implantado em escola pública do Paranoá, Projeto de inclusão digital para os estudantes do primeiro segmento do Ensino Fundamental da Educação de Jovens e Adultos. O intuito inicial do Projeto é o acompanhamento dos egressos da alfabetização do CEDEP na rede pública de ensino. Para isso, foram iniciadas atividades no laboratório de informática com vistas a integrar as linguagens de Português e matemática, com a linguagem informática e a proposta da Educação Popular, historicamente construída no CEDEP, que envolve: o acolhimento dos educandos e educadores, o trabalho com a situação problema-desafio vivido pelos educandos da EJA e a construção de textos coletivos, que são eixos do Genpex.

O trabalho desenvolvido no laboratório de informática envolve as quatro turmas do primeiro segmento da EJA e é coordenado por um grupo de estudantes do GENPEX vinculados a universidade de Brasília. Segundo Coelho e Cruz (2008, p.14) deixar de oferecer aos sujeitos da EJA "a possibilidade de adquirir os conhecimentos necessários a este novo código de comunicação da sociedade tecnológica, é negar-lhes o direito à plena cidadania, dada a penetração generalizada das tecnologias digitais na vida contemporânea". Ou seja, sem o acesso a esse conhecimento, “terão limitadas oportunidades de acessar informações em sites de órgãos governamentais, sindicais, de ONGs, informações das quais dependem muitos de seus interesses como pessoas, como trabalhadores, como cidadãos" (COELHO; CRUZ, 2008, p. 14).

A práxis que estrutura e sedimenta todas as propostas político-pedagógicas desenvolvidas no planejamento no laboratório de informática está fundamentada na situaçãoproblema-desafio, na construção de textos coletivos e na amorosidade/acolhimento. Portanto, a proposta político-pedagógica é construída com base no respeito às histórias de vida e saberes 
diversos dos educandos. No item a seguir, analisamos, com base nas contribuições da educação popular e do conceito de comunidades de práticas as significações atribuídas às experiências formativas vivenciadas no contexto da alfabetização de adultos do GENPEX por estudantes de Pedagogia em processo de formação inicial.

\section{A visão dos graduandos sobre a práxis vivenciada no contexto da Educação de Jovens e Adultos}

Em função da necessidade de acompanhar os egressos da educação popular iniciou-se um trabalho de inclusão digital na educação de jovens e adultos em escola pública, desenvolvido pelo CEDEP e UnB, por meio da articulação de estudantes do curso de Pedagogia. Nesse sentido, a parceria desenvolvida pelas Comunidades de Práticas CEDEP e UnB, definese por um processo expansivo da aprendizagem, uma vez que a prática de ensino no CEDEP não ficou "estacionada" na Alfabetização de Jovens e Adultos, mas também avançou de modo coletivo, ou seja, para uma aprendizagem expansiva na e com a inclusão digital (ENGESTRÖM, 1987).

A prática formativa estimulada pelo GENPEX inclui o acompanhamento pelo estudante de Pedagogia em classes de alfabetização, inclusão digital e a participação no planejamento das aulas, que em geral acontece às sextas-feiras, no movimento popular. A orientação dos estudantes pela equipe de professores da UnB ocorre uma vez por semana, onde além de se realizar a avaliação do andamento dos trabalhos, são tomados os encaminhamentos para o trabalho pedagógico realizado na semana posterior. É estimulada a reflexão e ação na e sobre a prática, bem como o registro das vivências em um diário de bordo, que é um dos instrumentos de avaliação da disciplina. Ao analisar esse material produzido pelos estudantes percebem-se diferentes formas de aproximação com o exercício docente na educação de jovens e adultos. Uma das estudantes consegue captar na estrutura da proposta o vínculo forte com a educação popular. Para ela,

A proposta desde o início do projeto 4 fases 1 e 2 foi a construção de um trabalho pedagógico com os educandos dentro de uma perspectiva de Educação Popular, baseada nos pressupostos metodológicos específicos, onde as ações estão alicerçadas pelas práxis Freiriana. Metodologias, conteúdos e intervenções pedagógicas foram centradas e articuladas com os educandos, sua voz, experiências, anseios, particularidades, relatos cotidianos e silenciamentos serviram de base para construção de uma proposta pedagógica de aprendizagem replicada na prática diária, que resultaram na produção de um saber autônomo e crítico. $O$ que se pretende evidenciar a partir dessa aproximação é o eixo estruturante das diferentes 
experiências dentro da educação popular, com uma proposta de educação que considere o estudante da Educação de jovens e adultos, um estudante com um percurso anterior a ser analisado e não rotulado.

O depoimento acima traz à tona a intencionalidade da proposta do GENPEX: trabalhar com pessoas excluídas, reconhecendo-as como sujeitos de poder, amor e saber. Partir de uma concepção humanizadora de Pedagogia, tal como preconiza Freire, no qual ao invés de me "sobrepor aos oprimidos e continuar mantendo-os como quase "coisas", com eles estabeleço uma relação dialógica permanente (2014, p. 77). Ela também percebe o vínculo do trabalho com a educação popular. Não obstante, a educação popular ter vivido o seu apogeu na década de 60, sua influência se faz presente no Brasil e no mundo, no ideário e na prática de diversas organizações populares. Para Brandão (2008), a educação popular não é uma escola pedagógica, nem uma proposta datada e de "aprendizagem situada" em um tempo específico. Ela é uma vocação da educação, um instrumento político e cultural de força pedagógica a serviço das classes populares. Em consonância com Brandão, autores, como Lave e Wenger (1991) da teoria da aprendizagem situada, afirmam que a educação e a aprendizagem não podem ser confundidas com a noção de localismo, obrigatoriedade e limitações de um tempo com tarefas determinadas. Pois, compreendem que a educação e aprendizagem, “[...] é parte integral da prática social geradora no mundo em que se vive" (LAVE; WENGER, 1991, p. 04)

Também, segundo Brandão (2008), a proposta de uma educação popular pode ser viabilizada a partir de duas posturas distintas e não antagônicas: por um lado, com ênfase no seu viés político para preparar as classes populares para algum tipo de transformação social, subordinada a uma tomada de poder e à instauração de uma alternativa socialista à sociedade capitalista e opressora; e de outro, com ênfase no seu viés cultural, como forma de elevar, de uma maneira justa e não supletiva, a qualidade de vida dos excluídos, a começar pela oferta de um tipo de educação que instaure a plenitude da pessoa cidadã. Ou seja, é o "entendimento compreensivo que compromete a pessoa na totalidade, em lugar da 'recepção' de um corpo de conhecimento fatual sobre o mundo, e na proposta de que a pessoa, a atividade, e o mundo se constituem mutuamente uns aos outros" (LAVE; WENGER, 1991, p. 4).

Brandão argumenta que, ao mesmo tempo em que é necessária a ampliação de experiências autônomas de uma educação realizada a partir da iniciativa dos movimentos populares, é também fundamental a redefinição da escola pública de modo a que ela venha a se transformar em uma educação oferecida pelo Estado, mas que incorpora os anseios, interesses e necessidades das classes populares. 
Esta mesma aluna afirma que ao ser matriculada em Projeto 4 "o formato das aulas, o contato, convivência, generosidade, amorosidade, cuidado, interação, integração e compartilhamento em um primeiro momento causou estranhamento e uma certa desconfiança de como seriam sistematizadas as atividades de Projeto 4". Essa compreensão aos poucos foi reconstruída e após dois semestres consecutivos no Projeto ela afirmou que o que "que era uma disciplina, se tornou um aprendizado de vida". Ela também argumenta que as atividades realizadas durante todo o primeiro semestre agregaram sentido e significação aos 3 anos do curso de pedagogia.

Na mesma direção, outro estudante relata que reencontrou "sentido na educação através de um dos seus segmentos mais frágeis e ricos: a educação de jovens e adultos". Ele relata que, no grupo soube "dar voz a quem é silenciado, a dar carinho a quem não conhece o sentido da palavra, a acolher e conquistar através do coração as pessoas que desejam mudar suas vidas".

Essas reflexões realizadas a partir das experiências vivenciadas pelos graduandos, no CEDEP/GENPEX, traduzem a relação prática do processo formativo, mas também a organização sistemática e coletiva da comunidade em ações cotidianas de educação e aprendizagem, conforme foi compreendido por Lave e Wenger (1991). Um dos diferenciais do processo de alfabetização desenvolvido com o CEDEP é o acolhimento, a "amorosidade" com que as alfabetizandos (a) são tratados (REIS, 2011; FREIRE, 1996). Parte-se do pressuposto que quando se atua com pessoas as quais foi negado algo tão essencial como o acesso à escola e a própria língua escrita, trabalha-se com pessoas excluídas de várias formas e que não têm como habitual tal acolhimento. Ser acolhido no processo de alfabetização garante o bem-estar do educando e consequentemente a permanência do mesmo no ambiente educativo.

Uma estudante de Pedagogia relata que se surpreendeu ao presenciar o dessilenciamento dos educandos. "É bonito demais ver aquelas pessoas sabendo que têm voz". Ela conta que "ficava admirada com questões de política, direitos, história e muito mais. Aquelas pessoas possuem um conhecimento muito rico e somente agora que elas estão se dando conta disso". Esta estudante reflete sobre os saberes que estes sujeitos constroem ao longo da sua vida, o que traz à baila a necessidade dos alfabetizandos terem voz, vez e decisão. Para isso, é preciso que percebam que não são sujeitos que nada sabem, condição na qual eles mesmos se descrevem quando buscam ou são levados à alfabetização, mas que se vejam como protagonistas de suas próprias histórias. Uma vez que foram silenciados, “a língua, a palavra são quase tudo na vida humana" (BAKHTIN, 2003, p. 324) encontrar pessoas (alfabetizadoras) que estão dispostas a ouvi-los com amorosidade e atenção facilita muito a apreensão da alfabetização num sentido amplo, uma alfabetização transformadora e libertadora. 
Além de perceber a importância do acolhimento e dessilenciamento, os estudantes de Pedagogia tornam-se sensíveis às condições desumanas presentes na negação do direito à educação. Percebem que participar do trabalho de alfabetização de adultos numa perspectiva de pesquisa-ação os torna mais sensíveis aos processos produtores de desigualdades na sociedade brasileira. Ao mesmo tempo, reconhecem que a alfabetização e a escolarização de jovens e adultos é algo transformador para os sujeitos, pois ao se apropriarem da leitura e da escrita o alfabetizando passa por um processo de mudança pessoal que afeta vários aspectos de sua vida: "Tudo muda... suas posturas, de cabisbaixas e silenciosas, até mesmo envergonhadas, para pessoas mais felizes e sorridentes" (estudante).

É importante reiterar que em 2015, devido à paralisação das atividades do Brasil Alfabetizado, o CEDEP iniciou trabalho de acompanhamento em escola pública do Paranoá, utilizando a informática e a escuta dos estudantes como estratégia de intervenção pedagógica. Com base na partilha e em um trabalho interativo, buscou-se construir o planejamento de metodologias que pudessem dialogar com a realidade percebida e vivida por cada educando.

No início, foram encontradas algumas dificuldades no desenvolvimento das atividades, pois alguns professores não aceitavam o trabalho por acreditarem que o conteúdo seria prejudicado; a direção da escola também colocava empecilhos para aceitar o projeto. Não obstante, os estudantes tentaram manter uma perspectiva dialógica e propositiva. Ao avaliar esse processo, uma estudante se manifesta:

Nós da Pedagogia, ficamos responsáveis por essa turma do primeiro horário de segunda-feira, e foi o dia que eu escolhi para estar participando do projeto. Pude acompanhar a turma e ver o crescimento de muitos, mas também a frustração de alguns por não conseguirem achar as letras no teclado, ou clicar com o mouse, e vi e aprendi como é importante nessas horas a figura do professor que motiva e acredita no potencial do aluno. Muitos queriam desistir, mas quando nós insistíamos e eles tentavam mais uma vez e conseguiam realizar o exercício, o que para nós poderia ser pouca coisa, para eles era uma grande vitória. Foi assim todos os dias, cada um a seu tempo avançando.

Percebe-se que a prática pedagógica desenvolvida em escola pública do Paranoá foi marcada pela escuta sensível das histórias de vida dos educandos, pelo diálogo e negociação com os gestores e professores acerca da importância do projeto para a aprendizagem e desenvolvimento dos educandos jovens e adultos. Esse processo foi salutar para o reconhecimento e ressignificação de suas concepções e preconceitos em torno da EJA, processo que ultrapassa o âmbito das salas de aulas da universidade, e que instaurou no educando/futuro professor convicções acerca das suas opções profissionais. 
o semestre mudou muito em mim e naqueles que estão ao meu redor porque foi perceptível a minha alegria por estar no projeto e por ele ser na EJA, $e$ também a minha posição com relação a outros assuntos.[...] consegui quebrar muitos preconceitos que tinha com relação ao Paranoá e o seu povo, e isso só aconteceu por meio das nossas conversas, dos relatos das vertentes e pela experiência/prática que tive na Escola do Paranoá.

Desse modo, com base nas falas e análises realizadas, anteriormente, é possível perceber que o percurso dos graduandos na experiência formativa no CEDEP/GENPEX, processualmente os levam a mudanças de concepções, de transformações pessoais, bem como das pretensões profissionais, em função também, da compreensão do processo histórico da comunidade, da constituição de sua identidade, ou seja, das características próprias que definem a prática/ação do CEDEP, assim como, da compreensão das histórias de vida dos sujeitos envolvidos na Alfabetização e do movimento coletivo que organiza a educação e a aprendizagem, para que ocorra de modo expansivo e continuado (ENGESTRÖM, 1987; LAVE; WENGER, 1991).

\section{Considerações finais}

Nesse artigo, analisamos a experiência do curso de Pedagogia da Faculdade de Educação no tocante à formação de educadores de EJA, com base no trabalho desenvolvido nos projetos 3 e 4. Nossa pretensão não foi a de esgotar as informações acerca desse tema, mas constituir uma reflexão inicial acerca das possibilidades formadoras dos diversos espaços disponíveis no âmbito da FE/UnB. Percebe-se no desenvolvimento do trabalho do GENPEX a intencionalidade de construir uma formação inicial em EJA com base nos pressupostos da educação popular. Para tanto, a pesquisa-ação possibilita ao futuro professor a vivência e o desenvolvimento de uma prática pedagógica pautada na escuta sensível, no diálogo, na amorosidade e no respeito mútuo. A análise das falas revela indícios de que o contato com os sujeitos jovens e adultos e a reflexão na e sobre essa experiência forja no estudante de Pedagogia uma sensibilidade/compromisso em relação a essa realidade.

\section{REFERÊNCIAS}

BAKHTIN, M. Estética Da Criação Verbal. 4. ed. São Paulo: Martins Fontes, 2003.

BARBIER, R. A pesquisa-ação. Trad. Lucie Didio. Brasília: Liber Livro, 2002. 
BRANDÃO, C. R. A educação popular antes e agora. Formação de educadores de jovens e adultos / organizado por Maria Margarida Machado. Brasília: Secad/MEC, UNESCO, 2008.

BRASIL. Ministério do Planejamento, Desenvolvimento e Gestão/IBGE. Pesquisa Nacional por Amostra de Domicílios - PNAD 2015. Rio de Janeiro, 2016.

COELHO, S. L. B.; CRUZ, R. M. R. Limites e possibilidades das tecnologias digitais na Educação de Jovens e Adultos. 31 ${ }^{\text {a }}$ Reunião da ANPED. Caxambu,2008.

ENGESTRÖM, Y. Learning by expanding: an activity-theoretical approach to Developmental research. Helsisnki: Orienta-Konsultit, 1987. Disponível em http://lchc.edu/MCA/Paper?Engestrom/expanding/ch1.htm. Acesso em: 10 nov. 2017.

FREIRE, P. Pedagogia da autonomia: saberes necessários à prática educativa. São Paulo: Paz e Terra, 1996.

FREIRE, P. Pedagogia do Oprimido. 52. ed. Ver e atual. Rio de Janeiro: Paz e Terra, 2014.

LAVE, J.; WENGER, E. Situated Learning. Legitimate peripheral participation. New York: Cambridge University Press, 1991 (16th. Printing). Traduccion de Miguel Espíndola y Carlos Afonso. Supervisión de la traducción: Giovanna Winchkler. Disponível em: https://www.Moodle.ufba.br/file.php/10203/.../wenger.pdf. Acesso em: 02 set. 2017.

REIS, R. H. A Constituição do Ser Humano amor, poder, saber na educação de jovens e adultos. 1. ed. São Paulo. Autores Associados. 2011.

THIOLLENT, M. Metodologia da pesquisa-ação. SP: Cortez, 1985.

WENGER, É. Communitiesof Practice: Learning, Meaning, And Identity. New York: Cambridge University Press, 1998.

UNIVERSIDADE DE BRASÍLIA. Faculdade de Educação. Projeto Acadêmico do Curso de Pedagogia. Brasília: Faculdade de Educação, 2002.

VIEIRA, M. C.; REIS, R. H.; SOBRAL, J. B. L. Educação de jovens e adultos como ato de amor, poder e saber: Os desafios do Genpex. Brasília (DF): Fundação Universidade de Brasília, Decanato de Ensino de Graduação, 2015.

VYGOTSKY, L. S. Teoria e método. 1. ed. São Paulo: Martins Fontes, 1996

VYGOTSKY, L. S. Psicologia infantil (Incluye: "Paidologia infantil". "Problemas de la psicologia infantil"). Tomo IV. Madrid: Visor, 2006. 


\section{Como citar este artigo:}

VIEIRA, Maria Clarisse. Comunidades de práticas como espaços de formação inicial na educação de jovens e adultos. Revista Ibero-Americana de Estudos em Educação, Araraquara, v. 14, n. 3, p. 1015-1029, jul./set., 2019. e-ISSN: 1982-5587. DOI: 10.21723/riaee.v14i3.11139

Data de Submissão: $28 / 02 / 2018$

Revisões requeridas: $30 / 04 / 2018$

Aceite em: 29/07/2018

Publicado em: 29/03/2019 